\title{
España en la Europa hitleriana
}

\author{
Rafael García Pérez
}

Las relaciones hispano-alemanas durante la Segunda Guerra Mundial han sido fuente de confrontación política, e historiográfica, desde el momento mismo en que se produjeron estos acontecimientos, a comienzos de los años cuarenta. Las razones son bien conocidas por todos y no es necesario incidir nuevamente sobre ellas. La colaboración recíproca entre el Estado franquista y el Tercer Reich, desde 1936, legó al régimen español un pesado déficit político que impidió, en primera instancia, y finalmente condicionó, la inclusión de España en el sistema internacional creado por los vencedores a partir de 1945. Lo que en algunas ocasiones se ha denominado "el estigma» del régimen ${ }^{1}$, lastró a la dictadura franquista tanto o más que su falta de legitimidad democrática o que sus repetidos atropellos contra los derechos humanos. Frente a esta losa del pasado, la dictadura trenzó, como en tantos otros asuntos, una red de mistificaciones y concienzudas falsificaciones del pasado tratando de salvar, e incluso idealizar, a la figura del dictador. Una de las tareas de manipulación histórica más conseguida fue la que presentó al general Franco como el hombre capaz de decir no a Hitler y mantener a España al margen de la guerra mundial.

La repercusión del "mito de Hendaya» desbordó, hace tiempo, las misiones para las que fue concebido. En principio fue una eficaz arma de combate para neutralizar a un posible rival político (Ramón Serrano Súñer), al que se le atribuyó la responsabilidad exclusiva del pro-nazismo del régimen. A partir de 1945 fue un argumento reiterado que trataba de limitar la implicación española en la contienda mundial ${ }^{2}$. Y desde

PIKE, D.W.: “El estigma del Eje», en: Historia 16, n 115/1985, pp. 50-66.

2 Las publicaciones que defendieron esta idea fueron muchas y de desigual alcance, entre ellas cabe destacar: GonzÁLEZ, S.: Diez años de historia difícil: indíce de la neutralidad española, 
hace muchos años es una machacona cantinela utilizada por la propaganda política, y difundida de modo más eficaz por cierta historiografia española ${ }^{3}$ que ha calado hondo en la conciencia colectiva de los españoles y, aún en la memoria de muchos ciudadanos ilustrados europeos. Frente a la sucesiva caída de otras fábulas franquistas ${ }^{4}$, en la actualidad, el mito de la neutralidad sigue surgiendo, de manera espontánea, en conversaciones no académicas, a la hora de enjuiciar la labor del dictador, y se sigue presentando como el principal activo del régimen, contando con un reconocimiento prácticamente unánime ${ }^{5}$.

Poco efecto social parecen haber tenido las investigaciones históricas que sobre fuentes documentales directas han sido publicadas. Algunas ya lejanas, como es el caso del estudio del profesor Donal S. Dentwiler ${ }^{6}$ que, incomprensiblemente, sigue sin ser traducido al castellano. Otras obras más recientes, escritas por investigadores españoles durante la recuperación democrática, tuvieron mayor difusión entre los estudiosos y han quedado como obras de referencia obligada ${ }^{7}$, aunque sus tesis principales siguen ignoradas por lo que podríamos denominar el "gran público" culto.

Los efectos que tiene la pervivencia del "mito de Hendaya" van más allá de la constatación de que la memoria colectiva de los pueblos y la

Madrid, Espejo, 1947; Rio Cisneros, A. del: España rumbo a la posguerra. La paz española de Franco, Madrid, Europa, 1947. Dentro de esta onda, aunque de mayor altura intelectual, se encuentra la obra de Doussinague, J.Ma .: España tenia razón, 1939-1945, Madrid, Espasa-Calpe, 1949.

3 Sus más genuinos representantes siguen siendo, en la actualidad: LA CIERVA, R. de la: Francisco Franco. Biografía histórica, Barcelona, Planeta, 1982 (10 vol.) y SUÁREZ FEANÁNDEZ, L.: Francisco Franco y su tiempo, Madrid, Fundación Nacional Francisco Franco, 1984 (8 vol.).

4 Muchas de elias combatidas con denuedo, como en el caso del investigador norteamericano Southworth, H.R.: El mito de la cruzada de Franco, Barcelona, Plaza y Janés, 1986 (1 $1^{\text {a }}$ ed., París 1963). Entre los autores españoles cabe una mención especial a las obras del profesor VIÑAS, A.: La Alemania nazi y el 18 de julio, Madrid, Alianza, 1977; y El oro de Moscú. Alfa y omega de un mito franquista, Barcelona, Grijalbo, 1979.

5 Como ejemplo de este estado de opinión cabe mencionar el reportaje especial dedicado por la BBC británica a la figura del general Franco con motivo del centenario de su nacimiento, en 1992.

6 DENTWILER, D.S.: Hitler. Franco und Gibraltar. Die Frage des spanischen Eintritts in den Zweiten Weltkrieg, Wiesbaden, Franz Steiner, 1962.

7 Me refiero a la generación de historiadores españoles que comenzaron a publicar en los años setenta, entre los que destaco, para este tema, a: MARQUINA, A.: La diplomacia vaticana y la España de Franco (1936-1945), Madrid, CSIC, 1983; Tusell, J. y QUeIPO DE LLANO, G.: Franco y Mussolini. La política española durante la Segunda Guerra Mundial, Barcelona, Planeta, 1985; y Viñas, A. (y otros): Política comercial exterior en España (1931-1975), Madrid, Banco Exterior, 1979. 
actividad científica de sus historiadores discurren por caminos separados. El «mito de Hendaya» ha proyectado una linea de sombra sobre nuestra historiografía al convertir un problema fundamental de nuestro pasado reciente (la dimensión internacional del régimen franquista en su conformación como dictadura) en un asunto falsamente manido, ya conocido por todos e ignorados socialmente.

Mi intención desde estas páginas es proponerles una visión diferente sobre esta cuestión, obviando el debate sobre la beligerancia española y analizando, en cambio, las relaciones realmente establecidas entre España y Alemania durante aquellos años. En mi opinión, la clave de esas relaciones bilaterales no radica en la abstención española a participar militarmente, y de forma plena, en la contienda mundial. Lo que permite comprender la evolución de esta relaciones bilaterales no es el estudio de una opción finalmente no consumada sino, por el contrario, el análisis de los vinculos realmente establecidos. Poner de manifiesto la existencia de esa vinculación, de naturaleza genuinamente económica, y destacar la primacía que adquirió en la evolución de las relaciones hispano-alemanas en aquellos años constituye el objetivo del presente trabajo ${ }^{8}$.

En mi exposición voy a abordar, tan sólo, los primeros años de vida del régimen, etapa que transcurre entre la invasión de Polonia y el desembarco aliado en las costas norteafricanas. Fechas que en nuestra cronología nacional habría que sustituir por el final de la guerra civil y la salida del Gobierno de Serrano Súñer.

Estos tres años largos fueron una etapa crucial en múltiples sentidos. El régimen español se caracterizaba, aún en esta época, por su indefinición institucional, reflejo de la heterogénea composición de la coalición vencedora en 1939. Los diferentes grupos políticos coaligados por la guerra conservaban sus perfiles ideológicos propios y aún no habían renunciado a imponer sus propios objetivos. Se enfrentaban, por lo tanto, en un conflicto de competencias para influir sobre la fisonomía que finalmente adoptara el Estado ${ }^{9}$. Conflicto que ofrecía una oportunidad abierta a la intervención de las potencias enfrentadas en la guerra europea.

8 Estas ideas conforman la tesis principal de mi libro, recientemente publicado: GaRCia PÉREZ, R.: Franquismo y Tercer Reich. Las relaciones económicas hispano-alemanas durante la Segunda Guerra Mundial, Madrid, Centro de Estudios Constitucionales, 1994.

9 Sobre los enfrentamientos ideológicos entre los diferentes grupos políticos en aquellos años, ver el estudio de: FERRARY, A.: El franquismo: minorias políticas y conflictos ideológicos, 1936-1956, Pamplona, EUNSA, 1993, en especial las pp. 137-178. 
Fue una etapa crítica en la que se produjo la transformación del régimen que pasa de ser una mera coalición, aglutinada por la guerra, a ser una dictadura personal caudillista. Es en esta misma época cuando se consuma el proceso de aprendizaje del general Franco en el ejercicio del poder, ejerciendo una función presidencialista, reguladora y de arbitraje que, con el tiempo, se hizo indiscutible ${ }^{10}$.

Por su parte, el Tercer Reich se encontraba en el cénit de su poder militar, con un proceso en marcha de redistribución territorial sobre el espacio continental europeo sobre el que ejercía plenamente su hegemonía. La Alemania nazi era contemplada desde España como un modelo de Estado y como la mejor opción de alianza internacional. Pero, al mismo tiempo, como una gran potencia dispuesta a intervenir en cuestiones internas y a sustituir la influencia económica que antaño habian mantenido los capitales franceses y británicos. Sobre este conjunto de expectativas y recelos se desenvolvieron las relaciones hispano-alemanas.

\section{LA FUNCIÓN DE ESPAÑA EN EL PROGRAMA BÉLICO ALEMÁN}

La península ibérica se encontraba al margen del programa de conquista del espacio vital que perseguía la política exterior nacional-socialista. Esta posición marginal no fue alterada, en sus rasgos esenciales, durante todo el período, pero es cierto que España entró a formar parte en los planes y necesidades estratégicas del Reich a partir de un hecho no premeditado, casi fortuito, como fue la intervención alemana en la guerra civil española.

La contribución nazi a la victoria franquista es un acontecimiento sobradamente documentado y conocido ${ }^{11}$ del que interesa destacar algunos hechos que alcanzaron influencia perdurable. El alineamiento internacional del franquismo con el Tercer Reich tuvo como punto de partida esta colaboración bélica que pese a su naturaleza política y militar encontró una forma de articulación esencialmente económica.

\footnotetext{
10 TUSElL, J.: La dictadura de Franco, Madrid, Alianza, 1988, pp. 150-153.

1 Entre su extensa bibliografía cabe destacar; ABENDROTH, H.H.: Hitler in der spanischen Arena, Paderborn, Schöningh, 1973; MERKES, M.: Die deutsche Politik im spanischen Bürgerkrieg, Bonn, L. Röhrscheid, 1969 ( $2^{a}$ ed.); ViÑAS, A.: Guerra, dinero y dictadura, Barcelona, Crítica, 1984; VIÑAS, A.: "Las condiciones internacionales", en: TUÑÓN DE LARA, M.: La guerra civil española 50 años después, Barcelona, Labor, 1985, pp. 126-197; WHEALY, R.H.: Hitler and Spain, University Press of Kentucky, 1989.
} 
En el verano de 1936, el Tercer Reich se encontraba sumido en una de sus mayores crisis económicas como consecuencia de la escasez de divisas convertibles, déficit que había restringido el volumen de las reservas disponibles de materias primas. Este estrangulamiento en el aprovisionamiento externo se pretendia combatir con la puesta en marcha del Plan Cuatrienal en el verano de ese mismo año ${ }^{12}$.

La aplicación de este plan supuso un giro importante en la concepción estratégica de la política comercial exterior alemana. La creación de una economía de guerra autosuficiente pasaba por asegurar la mayor independencia posible respecto del exterior, tanto en materias primas como en mercados. Por ello, a partir de esa fecha, el comercio exterior alemán, temiendo un bloqueo naval similar al padecido durante la Primera Guerra Mundial, se concentró en un grupo de socios comerciales, lo más cercanos posible, conectados por vía terrestre y cuyas exportaciones consolidaran las reservas alemanas de materias primas y alimentos ${ }^{13}$. El objetivo era conseguir, en un determinado espacio territorial, una corona de socios comerciales amigos $o$, cuando menos, neutrales. Un cordón comercial que ofreciera una independencia económica, lo más alta posible, buscando, además, una fórmula de relación con esos paises para que, en caso de conflicto, permanecieran en la órbita de sus armas. Se estaba iniciando la construcción de la llamada "economía de gran espacio" (Grossraumwirtschaft).

La intervención alemana en la guerra civil ofreció una gran oportunidad para cumplir en España estos objetivos ${ }^{14}$. El primero de ellos era obtener un amplio suministro en todo tipo de productos. En tan sólo tres años, Alemania alcanzó una posición hegemónica en el comercio exterior nacionalista transformando las tendencias seculares de los intercambios españoles orientados, tradicionalmente, hacia Francia y Gran Bretaña ${ }^{15}$.

12 Los objetivos proclamados del Plan eran procurar las condiciones económicas que permitieran llevar a la práctica el programa bélico del nazismo. En líneas generales, el Plan dio un fuerte impulso a la producción de armamentos, sustitutos sintéticos y al acaparamiento de materias primas. Sobre el particular, ver la monografía del profesor PETZINA, D.: Autarkiepolitik im Dritten Reich, Stuttgart, Deustsche Verlags-Anstatt, 1968, pp. 45 y ss.

13 Volkmann, H.E.: “Aussenhandel und Aufrüstung in Deutschaland 1933 bis 1939", en: Forstmeier, F. y VOLKMANN, H.E. (eds.): Wirtschaft und Rüstung am vorabend des Zweiten Wektkrieges, Düsseldorf, Droste, 1981, p. 101.

14 El primer autor que puso en relación la aplicación del Plan Cuatrienal con la intervención en España fue: SCHIEDER, W.: “Spanischer Bürgerkrieg und Vierjahresplan. Zur Struktur natiionalsozialistische Aussenpolitik", en: MiCHALKA, W. (ed.): Nationalsozialistische Aussenpolitik, Darmstadt, Wissenschaftliche Buchgesellschaft, 1978, pp. 325-359.

15 Los productos más codiciados eran: materias primas minerales, alimentos, lana y derivados 
Lo interesante de este proceso acelerado de control comercial fueron los mecanismos que se emplearon para realizarlo. La clave de este proceso se encuentra en la forma en que se organizó la ayuda militar alemana a los sublevados españoles. Como el bando nacionalista carecía de recursos monetarios suficientes para hacer frente al pago de los suministros bélicos, Alemania los facilitó a crédito a través de una empresa privada, de nueva creación, controlada por militantes nazis y adscrita a la organización del Plan Cuatrienal. Esta compañia fue la conocida Hisma cuya actividad fue complementada por otra empresa en Berlín denominada Rowak. El consorcio Hisma-Rowak creó un sistema especial de compensación sistemática de mercancías que comprendía todos los intercambios estatales bilaterales y la inmensa mayoría del comercio privado ${ }^{16}$. El sistema presentaba la ventaja de regular un gran volumen de intercambio sin necesidad de emplear divisas libres convertibles, que era el principal estrangulamiento económico para los dos paises. Alemania obtenía el mayor volumen posible de materias primas españolas, mientras que los nacionalistas obtenían a crédito los suministros militares que le permitirian ganar la guerra. De esta manera, el Tercer Reich cumplia su segundo objetivo: asegurarse el suministro de materias primas insustituibles, sin necesidad de desembolsar divisas y a unos precios inferiores a los que regían en el mercado internacional.

El desarrollo de la guerra civil permitió a Alemania cumplir un tercer objetivo: establecer en España unas bases productivas directamente controladas por el Plan Cuatrienal y centradas en la producción y exportación de productos básicos para su producción de guerra. Esta estrategia económica empezó a perfilarse tras la conquista de la cornisa cantábrica (con sus depósitos de minerales) por las fuerzas franquistas en 1937 y se consumó al año siguiente con la creación de un holding empresarial denominado Sofindus. La Sofindus, directamente controlada desde Berlín, llegó a disponer de una quincena de empresas que desarrollaban su actividad en sectores clave: el comercio, los transportes y la explotación minera, principalmente. De esta manera, el Plan Cuatrienal daba un paso importante dentro de su estrategia europea, tras conseguir controlar la exportación comercial de algunos países conseguía establecer bases de producción propia en el extranjero. Para capitalizar estas operaciones de penetración económica contaban con una

quimicos. RuHL, K.J.: “L' alliance ă distance: les relations économiques germano-espagnoles de 1936 à 1945", en: Revue d' Histoire de la Deuxième Guerre Mondiale, n² 118/1980,pp. 69-102.

16 Ver las explicaciones que sobre el funcionamiento de este mecanismo comercial ofrece el profesor Viñas (y otros): La política comercial exterior..., vol. I, pp. 148-149. 
peculiar fuente de financiación, la deuda de guerra contraída por el ejército nacionalista que fue liquidada a lo largo de la guerra mundial.

Pese a que estas conquista alemanas atentaban contra los intereses económicos españoles e, incluso, vulneraban parcelas de soberanía del incipiente Estado franquista, la dependencia absoluta respecto de la ayuda militar obligó a consentir lo que, en puridad, podríamos denominar un proceso de penetración pseudocolonial. Es preciso recordar que estos aspectos "técnicos» de la cooperación bilateral eran totalmente reservados y que el clima general de las relaciones vivía una etapa de exaltación entusiasta. Los militares, grupo fundamental en el seno de la coalición nacionalista, se encontraban fascinados por la organización y desarrollo tecnológico de que hacía gala el Tercer Reich. La enorme extensión social que adquirió la Falange contribuyó, además, a que los sentimientos de admiración y gratitud derivasen hacia una afinidad ideológica. La intervención alemana fue presentada internacionalmente $y$, en muchos casos, también percibida desde España, como un acto de solidaridad anticomunista que iniciaba una etapa de colaboración política en defensa de unos intereses comunes.

Esta cooperación diplomática se materializó con la firma de diversos tratados. Un Convenio Cultural (24.1.39) que nunca se llegó a ratificar por las presiones vaticanas ${ }^{17}$, el Tratado de Amistad bilateral (31.3.39) y la adhesión española al Pacto Antikomintern (27.3.39). Poco tiempo después (el ocho de mayo), España se retiraba de modo oficial de la Sociedad de Naciones. El alineamiento internacional del nuevo Estado con el Eje no ofrecía duda alguna. Su única limitación fue que esta colaboración no alcanzó al compromiso de una alianza militar. No supuso ninguna fisura, al contrario. El tipo de vinculación diplomática establecida se ajustaba, de modo preciso, a las propias necesidades estratégicas del Tercer Reich.

A partir de 1938 el escenario estratégico europeo había cambiado. Resultaba cada vez más probable un enfrentamiento directo contra Gran Bretaña que se desarrollaría en el mar. Estas nuevas circunstancias revalorizaban la posición española. Así quedaba de manifiesto en un interesantísimo informe del jefe del Estado Mayor de la Marina de Guerra ${ }^{18}$. En él establecía que el principal objetivo estratégico de Alemania en la

17 Sobre las tensiones diplomáticas entre la Iglesia Católica y el Estado Español a raiz de este convenio véase: MARQUINA: La diplomacia vaticana..., pp. 142-153.

18 "Contribución a las deliberaciones del Ministro de Asuntos Exteriores en un hipotético Tratado que se ha de concluir con la España nacionalista al terminar la guerra" (Berlín, 26.4.38); reproducido en WATT, D.C.: "Germany's Strategic Planning and Spain 1938-1939", en: The Great Britain Army Quaterly and Defense Journal, $n^{\circ}$ 2/1990, pp. 221-223. 
península ibérica era conservar una España neutral en caso de conflicto. Esta neutralidad, benévola en razón de los lazos creados durante la intervención, sería instrumentalizada para servir a los intereses del Reich en el campo estratégico (como base de observación y apoyo logístico), económico (suministrando y explotando materias primas vitales) y diplomáticos (favoreciendo una actitud proalemana en los países de su entorno). Es preciso destacar que en los cálculos militares alemanes siempre se valoró más la contribución de España como aliada pasiva que como potencia militar. La vinculación diplomática al Eje no pasaba, pues, por la alianza militar, sino por un estatuto de neutralidad benevolente.

Al concluir la guerra civil el Tercer Reich podía hacer un balance favorable de la intervención. Se había conseguido establecer una sólida base de penetración política y económica sobre un espacio geográfico no contemplado en los planes originales del Lebensraum y que completaba la dimensión continental de su proyecto de expansión, mejorando las condiciones estratégicas de una futura batalla intercontinental (contando ya con Africa y América). Por su parte, los nacionalistas españoles habian alcanzado la victoria a un alto precio. De la guerra se heredaba una satelización política que los dirigentes del nuevo Estado consideraban beneficiosa, al estar convencidos de que el nuevo orden europeo haria evolucionar los gobiernos hacia regímenes autoritarios como los que pretendían mimetizar ${ }^{19}$. La guerra también legaba una carga de dependencia económica consecuencia de la penetración alemana (de modo especial en el sector minero), la pérdida del control del comercio exterior y la existencia de una abultada deuda de guerra. A pesar de que estos hechos atentaban contra los principios nacionalistas verbalmente defendidos por el régimen, los nuevos gobernantes se mostraban convencidos de la necesidad de contar con la participación alemana en el proceso de reconstrucción, asociando la prosperidad nacional con el futuro de la potencia hegemónica. Eliminado el componente militar, a partir de 1939, el factor económico se convirtió en el eje esencial de las relaciones bilaterales.

\section{LOS CAMBIOS EN LA POSGUERRA}

El final de la guerra civil abría una etapa de incertidumbre en casi todos los terrenos que, en muchos casos, fueron pronto despejadas.

19 Sobre la difusión de ese estado de opinión véase el articulo: GARCiA PÉREZ, R.: «La idea de la "Nueva Europa" en el pensamiento nacionalista española de la inmediata posguerra, 19391944 ", en: Revista del Centro de Estudios Constitucionales, nº 5/1990, pp. 203-240. 
Ideológicamente, la dictadura se reafirmó en aquellos rasgos externos que más la asimilaban a los modelos fascistas europeos. Todos los pasos que dio el régimen en la esfera internacional confirmaron su vinculación diplomática con el Eje. Y esta afinidad ideológica llegó a determinar, incluso, la política de reconstrucción. Fueron rechazados los créditos ofrecidos por las potencias occidentales en función de consideraciones políticas ${ }^{20}$. Y también por razones políticas se asumió un programa económico basado en el crecimiento acelerado sobre la base de la producción militar y una dirección férreamente intervencionista y dirigista. El programa autárquico se ponía en marcha, desde la tradición del nacionalismo económico español de las décadas anteriores y sobre el ejemplo de ios Estados totalitarios europeos. El objetivo era recuperar para España la condición de potencia europea, estatuto que en la mentalidad de los nuevos dirigentes iba asociada a la conquista de un nuevo imperio colonial.

Con respecto a las relaciones bilaterales, la principal aspiración del Gobierno nacionalista era sustituir el sistema privado Hisma-Rowak por un acuerdo interestatal convencional que devolviera a España el control soberano sobre su comercio exterior. Por su parte, los representantes alemanes condicionaban la desaparición de la Hisma a su sustitución por un tratado general de comercio que España no se encontraba en condiciones de negociar. Faltaba todo tipo de informaciones básicas sobre la situación real del pais tras la guerra. Sobre esta penuria informativa era imposible negociar un acuerdo ventajoso. Se trataba, por tanto, de ganar tiempo para componer esa base informativa imprescindible que permitiera conducir la negociación con fundamento. La demora fue admitida por el Tercer Reich sin oponer resistencia, ya que venía a prolongar las ventajas irrepetibles obtenidas durante la intervención.

Los retrasos permitieron que la guerra europea comenzase sin haber alcanzado un acuerdo. Fue un golpe de suerte para el régimen franquista que le permitió eludir el tratado, sin duda, desequilibrado. La guerra modificó las condiciones estratégicas y las necesidades económicas de los dos socios. Alemania comenzaba a sentir las consecuencias del incipiente bloqueo aliado y trataba de asegurar el abastecimiento de determinados productos básicos. Era la primera manifestación de la dependencia alemana respecto de la producción española que permitió reforzar la posición negociadora de Madrid.

20 Viñas (y otros): Política comercial exterior..., vol. 1, pp. 280-289. 
${ }^{21}$ El nuevo convenio fue firmado en diciembre de 1939 y supuso un notable éxito diplomático para el Gobierno español. La exclusividad del sistema de compensación privado Hisma-Rowak fue sustituido por un acuerdo interestatal controlado por los respectivos órganos oficiales, el Instituto de Moneda Extranjera y la Caja Alemana de Compensación (Deutsche Verrechnungskasse). Se reestablecia el tráfico de capitales particulares y la actividad comercial privada. Aunque no se eliminasen las estructuras económicas-socialistas (dentro del entramado Sofindus), el Estado español recuperaba los resortes elementales que le permitían controlar su comercio exterior y la libertad para suscribir acuerdos comerciales con terceros paises ${ }^{22}$.

EI Tercer Reich no ofrecía estas concesiones de forma gratuita. Obtenía de España el compromiso de facilitar, para su exportación, la mayor cantidad posible de determinados productos, señalados previamente por Alemania: minerales (hierro, piritas, plomo,...) y alimentos (aceite, cítricos, ...) que junto a la lana y el cuero revelaban la función suministradora de materias primas que la planificación bélica alemana había otorgado a España. Obtenía, además, el compromiso español de "estudiar la situación» de la deuda de guerra contraida, con la intención de proceder a su posterior liquidación. Recursos que los administradores del Plan Cuatrienal trataban de emplear en consolidar y ampliar la red de explotaciones adquiridas en España a través de la Sofindus.

Si algunos círculos del Tercer Reich mostraron su desacuerdo ante la firma de este acuerdo ${ }^{23}$. La razón principal de su disentimiento no era tanto el convenio como sus resultados comerciales. La sensible reducción de la exportación española hacia Alemania, en la primera mitad de 1940, fue consecuencia de la incapacidad alemana para vulnerar el bloqueo aliado (estando las comunicaciones terrestres interrumpidas a través de Francia) y no la aplicación escrupulosa del nuevo convenio. El problema

21 La versión alemana del Acuerdo Comercial (del 22.12.39) se encuentra publicada en Akten zur deutschen auswärtige Politik (en adelante ADAP), serie D, vol. VIII, doc. 482. La versión española en: Colección de Tratados Internacionales suscritos por España (en adelante CTISE), vol. VI, tomo I, pp. 495-506.

22 El Gobierno nacionalista se habia comprometido durante la guerra civil (Protocolo del 12.7.37) a firmar con Alemania un acuerdo general económico al terminar la guerra y que fuera Alemania el primer país en concluir un acuerdo de estas caracteristicas. ADAP, D, III, DOC. 392 y CTISE, VI, I, pp. 269 y ss.

23 Göring y todo el entramado dependiente del Plan Cuatrienal. Conferencia de Karinhall (16.3.40). ADAP, D, VIII, doc. 678. En esta reunión se determinó que el objetivo en España era "sacar todo lo que tuviera valor económico". 
del suministro era una cuestión estratégico-militar y no política, como se pondría de manifiesto tras la caída de Francia.

\section{EL MOMENTO DE LA GRAN TENTACIÓN}

El nuevo equilibrio alcanzado fue roto por la fulgurante victoria alemana sobre Francia. La ambición imperialista del Gobierno español, tratando de aprovechar la nueva situación creada, desencadenó una serie de consecuencias cuyo resultado estuvo a punto de desbordarle.

La declaración española de «no beligerancia» y, sobre todo, la disposición del franquismo a participar en la contienda, comunicada de manera explicita a Hitler en junio de $1940^{24}$ implicaba, de forma inmediata, una redefinición de las relaciones bilaterales. Para el Tercer Reich, la participación española en la guerra no tenía un valor de cambio suficiente que permitiera compensar sus aspiraciones territoriales en el Norte de Africa. Por esta razón se consideraba imprescindible la redacción de un protocolo en el que fueran especificadas, de forma previa, las contraprestaciones que debía asumir el Gobierno español. Compromisos que se revelaron sumamente amplios: militares, territoriales, políticos y, esencialmente, económicos ${ }^{25}$.

En las negociaciones hispano-alemanas celebradas entre septiembre y noviembre de $1940^{26}$, se pusieron de manifiesto todas estas implicaciones que superan las previsiones realizadas por los gobernantes españoles. Desde la inclusión de algunos territorios nacionales (una isla canaria) en el nuevo reparto colonial, a la suplantación por el capital alemán de la influencia ejercida sobre la producción minera española por las compañías británicas y francesas.

A lo largo de estas negociaciones se sentaron las bases de lo que hubiera sido el futuro de las relaciones bilaterales de consumarse la beligerancia.

24 El general Vigón expuso directamente ante Hitler el programa imperialista español. Acta de la conversación Hitler-Vigón-Ribbentrop (16.6.40) en: ADAP, D, IX, doc. 456.

25 El primer borrador de este protocolo fue esbozado por el embajador en Madrid (Stohrer) en carta a Ribbentrop (Madrid, 16.8.40), ADAP, D, X, doc. 405.

${ }_{26}$ Su contenido ha sido suficiente estudiado. Sobre los aspectos estratégicos: Buroick, Ch. B.: Germany's Military Strategy and Spain in World War II, Syracuse University Press, 1968, pp. 35-95. Sobre las cuestiones políticas: DENTWILER, D.S.: Hitler, Franco und Gibraltar, pp. 37-79; y Ruiz Holst, M.: Neutratlität oder Kriegsbeteiligung. Die deutschspanischen Verhandlungen iJahre 1940, Pfaffenweiler, Centaurus, 1986, pp. 91-134.Sobre la dimensión económica: GARCía PÉREZ, R.: Franquismo y Tercer Reich, pp. 174-197. 
Sobre muchos aspectos se alcanzaron compromisos firmes, especialmente en el terreno económico ${ }^{27}$. Por ejemplo, el Gobierno español aceptaba un nuevo acuerdo especial para el suministro recíproco de mercancias que, en la práctica, suponía la reposición del antiguo mecanismo comercial utilizado durante la guerra civil. Los yacimientos de materias primas del antiguo protectorado francés en Marruecos serian cedidos, por entero, al Tercer Reich, que se comprometía a cubrir las necesidades españolas de estos minerales. Además, las empresas francesas y británicas instaladas en la península serían transformadas en una posesión conjunta hispano-alemana, asegurando la exportación hacia Alemania de toda la producción mineral en la medida que las necesidades españolas quedaran satisfechas.

Incluso se alcanzó un acuerdo en el terreno militar al mostrarse dispuesto el Gobierno español a participar en el Eje a suscribir un tratado de alianza miliar por un período de vigencia de diez años ${ }^{28}$. La única salvedad fue que España se reservaba el derecho de escoger el momento en que entraria en la guerra.

No hubo acuerdo, sin embargo, sobre la magnitud de la ayuda alemana y el momento en que sería entregada (antes o después de la declaración de guerra). Se trataba de una diferencia de concepto. Mientras que Alemania pensaba en una acción aislada y rápida para ocupar Gibraltar, el Gobierno español calculaba con defender todo el territorio nacional al que se incorporaría el Marruecos francés. $Y$, desde luego, no hubo reconocimiento, previo y por escrito, de las incorporaciones territoriales perseguidas por el Gobierno español. El Tercer Reich no podía aceptar esa anexión que iba a complicar, de forma extraordinaria, su posición estratégica en el Mediterráneo occidental.

Las negociaciones del otoño de 1940 demostraron la voluntad beligerante del Gobierno franquista y su vocación imperialista. Fueron admitidas, de forma previa y con carácter formal, las onerosas condiciones que la beligerancia imponía. Y lejos de constituir un obstáculo, el proyecto de imperialismo compartido ofrecido por el Tercer Reich fue el primer asunto sobre el que se alcanzaron acuerdos. Preso de su vocación imperialista, el régimen franquista no acertó a distinguir las servidumbres de esa supuesta

27 Nota del director del Departamento de Política Comercial del Ministerio alemán de Negocios Extranjeros (Wiehl) a Ribbentrop (Berlín, 28.9.40). Archivo Político del Auswártiges Amt (PP/AA), Handakten Wielhl, Spanien, Bd. 9. Dos partes importantes de este documento se en. cuentran publicadas en $A D A P, D, X I$, doc. 125 y 126.

${ }_{28}$ Informe del embajador Stohrer sobre la conversación mantenida con Serrano Súñer (25.9.40), ADAP, D, XI, doc. 104. 
grandeza compartida que, en la práctica, implicaba la subordinación de España a la potencia hegemónica nazi.

\section{LA CONFIRMACIÓN DEL PAPEL ESPAÑOL}

La falta de entendimiento con el Tercer Reich sobre los objetivos y los medios bélicos dejó al Gobierno español en, una posición delicada. No tanto porque Hitler insistiera en ejercer una presión irresistible (desde febrero de 1941 Ribbentrop prohibió cualquier mención sobre este asunto ${ }^{29}$ ) sino por el progresivo aislamiento internacional en que quedó sumido el régimen español y cuyas consecuencias más graves afectaron al abastecimiento externo de productos esenciales.

Las negociaciones sobre la participación española en la guerra fueron, en definitiva, la apertura frustrada de un nuevo modelo de relación entre los dos países. Fracaso, al igual que hubiera sucedido con su puesta en práctica, tuvo graves repercusiones. Cerradas las puertas a los grandes sueños, la realidad volvía a imponerse mostrando que la única posibilidad de profundizar las relaciones bilaterales pasaba por confirmar la misma vinculación económica que hasta entonces había existido. Una relación que Alemania no dejaria de explotar en beneficio propio aumentando de forma extraordinaria el desequilibrio comercial existente.

Este desequilibrio había sido una constante desde los tiempos de la guerra civil, pero en 1941 comenzó a adquirir dimensiones alarmantes. Las razones eran múltiples. El Tercer Reich, como todos los beligerantes, había incrementado su demanda al tiempo que perdía parte de su capacidad exportadora. Además, seguía una política de acaparamiento de materias primas (para asegurar la continuidad de su producción de guerra) que disparaba el volumen de sus compras. Desde mediados de 1940 las autoridades alemanas se habian esforzado por conseguir que el Gobierno español admitiera un desequilibrio comercial que empezó siendo de 40 mill. RM para convertirse en 70 mill. RM en mayo de 1941 y superar los 240 mill. RM en septiembre de $1942{ }^{30}$. Este desequilibrio comercial, que no generaba divisas ni, tan siquiera, compensación en productos, suponía en la práctica un préstamo que el Estado español concedia al Tercer

29 Telegrama $n^{\circ} 87$ de Ribbentrop a Stohrer (Fuschl, 22.2.41), ADAP, D, XII, doc. 73.

30 Telegrama $n^{\circ} 1.933$ de Wiehl a Stohrer (Berlín, 7.11.40), PA/AA, Handakten Wiehl, Spanien,Bd. 10; “Informe al Sr. Ministro» Gómez Jordana (19.9.42), Archivo del Ministerio de Asuntos Exteriores (AMAE) leg. R 2066/1. 
Reich. La consecuencia económica de esta enajenación política de la exportación nacional fue la escasez absoluta que vivió el mercado interior español de aquellos años.

La participación española en la agresión militar contra la Unión Soviética, en 1941, llevó implícito un incremento de sus responsabilidades en el esfuerzo bélico que ya se consideraba común. España participó en esta etapa decisiva de la guerra con dos contribuciones paralelas y complementarias: el envío de la División Azul y el reclutamiento de trabajadores para las fábricas alemanas de armamento.

La División Azul tuvo una repercusión militar insignificante, pero de gran alcance político. En el plano interno, consiguió reunificar a la dividida coalición que habia ganado la guerra civil, creando un nuevo consenso en torno al principal rasgo ideológico que compartían: el anticomunismo. En la escena internacional, el envío de la División tuvo unas repercusiones amplísimas al proporcionar un excelente argumento propagandistico para poner en marcha el proyecto continental nazi del Nuevo Orden europeo. Rescatando lemas ya utilizados durante la guerra civil, la invasión de la URSS se convirtió en una "cruzada antibolchevique" en defensa de la civilización europea en la que participaron, en mayor o menor medida, los once países más vinculados con el Tercer Reich ${ }^{31}$.

Al mismo tiempo, el gobierno alemán procedia a realizar otro reclutamiento de ámbito continental en el que España también participó: la aportación de mano de obra al esfuerzo de guerra alemán. Contribución que se mantuvo, de forma oficial, hasta comienzos de $1944{ }^{32}$. Aunque tanto por su gestación como por su desarrollo, ambas movilizaciones fueron diferentes, la sincronía en la ejecución y su evidente complementariedad obliga a considerar ambos hechos como manifestaciones distintas de una misma política integradora en el nuevo Orden europeo.

Estos dos reclutamientos continentales se encontraban unidos, en el caso español, por una finalidad común. Ambos fueron empleados para contribuir al pago de las antiguas deudas de guerra originadas durante la guerra civil y saldar, también, otras deudas morales, aunque minuciosamente cuantificadas, derivadas del envío de la Legión Cóndor. Pagos cuyo

31 Sobre la División Azul, otra de las cuestiones más estudiadas de esta época, cabe destacar dos obras: Kleinfeld, G./ TamBS, L.: La división española de Hitler, Madrid, San Martín, 1979; y Proctor, R.: Agonia de un neutral, Madrid, Editora Nacional, 1972.

32 Sobre el particular véase: GaRcia PÉREZ, R.: «El envio de trabajadores españoles a Alemania durante la Segunda Guerra Mundia", en: Hispania, n 170/1988, pp. 1.031-1.065. 
destino final no era otro que la financiación de las explotaciones mineras alemanas en la península.

La puesta en marcha del llamado Nuevo Orden, a partir de 1941 reafirmó a España en la posición esencialmente suministradora y productiva dentro de la organización económica bélica alemana ${ }^{33}$. Pese a todo, aún tardaría en percibirse esta realidad desde las instancias politicas españolas. Parecia ignorarse que el poderio militar del Tercer Reich pasaba por establecer su hegemonía industrial sobre Europa, limitando las capacidades productivas del resto de los países a la tarea de meros proveedores de in-put industriales. Esas necesidades eran satisfechas, en el caso español, por dos vias complementarias: el incontenible desequilibrio comercial en favor de Alemania y la red industrial, básicamente extractiva, en manos de la Sofindus. Durante el verano de 1941 se sumaría, además, la aportación laboral y, de manera tangencial, también militar.

Durante el periodo de influencia más intensa del Tercer Reich sobre España, desde los inicios de la intervención en la guerra civil, en 1936, hasta el desembarco aliado en el Norte de Africa, en el otoño de 1942, las relaciones hispano-alemanas estuvieron definidas por una predominante vinculación económica. Esta relación básica pudo ser modificada en un sentido militar (participando España en la guerra mundial) o político (vinculando al régimen franquista, aún más, a la órbita nazi), pero ambas modificaciones fueron rechazadas por los inconvenientes que amenazaban esa vinculación principal. La participación bélica española presentaba complicaciones estratégicas muy superiores a las posibles ventajas derivadas de su intervención. El estrechamiento de los lazos políticos, lo que en la práctica hubiera supuesto la definición del nuevo Estado en un sentido inequivocamente totalitario, creaba divisiones internas en el seno de la coalición victoriosa en 1939 que amenazaban con crear un nuevo conflicto. En uno y otro caso, el Tercer Reich prefirió preservar a la península de las amenazas bélicas y de la inestabilidad interna favoreciendo un estatuto de neutralidad que, en función de los lazos creados (en especial, el flujo comercial) constituia el mejor servicio que la empobrecida España, recién salida de la guerra civil, podía prestar.

Esta fórmula de vinculación básica quedó definida en 1936, desde que el Plan Cuatrienal alemán fijara como principal objetivo una enorme

33 No era un caso excepcional. Toda la estrategia bélica alemana pasaba por la "primarización" de sus socios y la anexión y explotación, como tierras de conquista, de sus enemigos. MILWARD, A.S.: Die deutsche Kriegswirtschaft 1939-1945, Stuttgart, Deutsche Verlags-Anstalt, 1966. 
producción industrial orientada hacia la guerra. Originariamente, la estrategia alemana situó, en el área danubiana y balcánica, las bases para obtener las materias primas necesarias. Pero el estallido de la guerra civil, y la riqueza mineral española, ofrecieron la oportunidad, y las razones, para que el territorio español fuera asociado a los intereses del Reich. El desarrollo de la guerra mundial, imponiendo un incremento incesante de la producción bélica, no hizo sino reforzar esta función suministradora. La ponderación económica y estratégica que recibian los suministros procedentes de España llegó al extremo de condicionar cualquiera de las decisiones nacional-socialistas relativas al régimen franquista, que siempre se orientaron a preservar el mantenimiento del vital flujo comercial en las condiciones económicas más favorables. 